\title{
Synthesis, Structural and Dielectric Properties of $\mathrm{SrBi}_{1.8} \mathrm{Ce}_{0.2} \mathrm{Ta}_{2} \mathrm{O}_{9}$
}

\author{
Mohamed Afqir ${ }^{1,2 *}$, Amina Tachafine ${ }^{2}$, Didier Fasquelle², Mohamed Elaatmani' ${ }^{1}$, \\ Jean-Claude Carru' ${ }^{2}$, Abdelouahad Zegzouti ${ }^{1}$, Mohamed Daoud ${ }^{1}$ \\ ${ }^{1}$ Equipe Sciences des Matériaux Inorganiques et Leurs Applications, Faculté des Sciences Semlalia, Université \\ Cadi Ayyad, Marrakech, Maroc \\ ${ }^{2}$ Unité de Dynamique et Structure des Matériaux Moléculaires, Université du Littoral Côte d’Opale, Calais, \\ France \\ Email: *mohamed.afqir@yahoo.fr
}

Received 9 February 2016; accepted 17 May 2016; published 20 May 2016

Copyright (C) 2016 by authors and Scientific Research Publishing Inc.

This work is licensed under the Creative Commons Attribution International License (CC BY). http://creativecommons.org/licenses/by/4.0/

CC) (i) Open Access

\section{Abstract}

This Ce-doped strontium bismuth tantalate $\mathrm{SrBi}_{1.8} \mathrm{Ce}_{0.2} \mathrm{Ta}_{2} \mathrm{O}_{9}$ was prepared by solid-state reaction. $\mathrm{X}$-ray diffraction was used to determine the crystal structure of the powders. The Raman spectrum of $\mathrm{SrBi}_{1.8} \mathrm{Ce}_{0.2} \mathrm{Ta}_{2} \mathrm{O}_{9}$ sample was measured to confirm X-ray diffraction result. The microstructure of ceramic was observed by Scanning Electron Microscope (SEM). The Temperature dependence of the dielectric properties of ceramic was investigated from the room temperature to $400^{\circ} \mathrm{C}$.

\section{Keywords}

Aurivillius, Solid-State, Electron Microscopy, Raman, Dielectric Properties, Electrical Conductivity

\section{Introduction}

These template, Aurivillius phase compounds, as bismuth layer-structured ferroelectrics are generally formulated $\left(\mathrm{Bi}_{2} \mathrm{O}_{2}\right)^{2+}\left(\mathrm{A}_{\mathrm{m}-1} \mathrm{~B}_{\mathrm{m}} \mathrm{O}_{3 \mathrm{~m}+1}\right)^{2-}$, where $\mathrm{A}$ is a mono, bi or trivalent ion, $\mathrm{B}$ a tetra, penta or hexavalent ion, and $\mathrm{m}$ the number of $\mathrm{BO}_{6}$ octahedral in each pseudo-perovskite block ( $\mathrm{m}=1$ to 5 ) [1]. Bismuth layer-structured ferroelectric materials have attracted an increasing attention for non-volatile Ferroelectric Random Access Memory (FeRAM) applications [2] [3].

$\mathrm{SrBi}_{2} \mathrm{Ta}_{2} \mathrm{O}_{9}$ has attracted much attention of researchers due to its fatigue-free properties in nonvolatile ferroelectric thin film random access memory applications [4]. The crystal structure has orthorhombic symmetry with $\mathrm{a}=0.5306 \mathrm{~nm}, \mathrm{~b}=0.55344 \mathrm{~nm}$ and $\mathrm{c}=2.49839 \mathrm{~nm}$; the theoretical density is $8.789 \mathrm{~g} / \mathrm{cm} \mathrm{[5]}$.

To our knowledge, there few studies talk about the substitution of bismuth by cerium in bismuth layered 
structured ferroelectrics systems. Cerium $\left(\mathrm{Ce}^{4+}\right)$ modified bismuth layered ferroelectric $\mathrm{SrBi}_{2} \mathrm{Ta}_{2} \mathrm{O}_{9}$ with general formula $\mathrm{SrBi}_{2-\mathrm{x}} \mathrm{Ce}_{3 \times / 4} \mathrm{Ta}_{2} \mathrm{O}_{9}(\mathrm{x}=0,0.025,0.05,0.075$ and 0.1$)$ was prepared by solid state reaction route. The morphological study was done by Scanning electron microscopy, which shows plate like structure. The temperature dependent dielectric study shows a diffuse phase transition with a linear decrease in transition temperature and dielectric constant with an increase in $\mathrm{Ce}^{4+}$ content [6].

Effect of Ce and La substitution on the microstructure and dielectric proprieties of $\mathrm{Bi}_{4} \mathrm{Ti}_{3} \mathrm{O}_{12}$ ceramics was investigated by Nikolina pavlovic et al. [7]. $\mathrm{Bi}_{4-\mathrm{x}} \mathrm{A}_{\mathrm{x}} \mathrm{Ti}_{3} \mathrm{O}_{12}$ ceramics were prepared by modified sol-gel method. Briefly, the addition of Ce improves diffuse phase transition and frequency dispersion of dielectric constant. It could be due to the characteristic nature of Ce. Cerium can change its oxidation sates easily between $\mathrm{Ce}^{3+}$ and $\mathrm{Ce}^{4+}$.

In order to investigate, we report solid solution of the Aurivillius type $\mathrm{SrBi}_{1.8} \mathrm{Ce}_{0.2} \mathrm{Ta}_{2} \mathrm{O}_{9}$, on microstructure and dielectric proprieties. However, our results and discussion were supported by the literature researches.

\section{Prepare Experimental}

First, $\mathrm{SrBi}_{1.8} \mathrm{Ce}_{0.2} \mathrm{Ta}_{2} \mathrm{O}_{9}$ (SBCT) powder was prepared by conventional solid-state reaction method using $\mathrm{Bi}_{2} \mathrm{O}_{3}$, $\mathrm{SrCO}_{3}, \mathrm{Ta}_{2} \mathrm{O}_{5}$ and $\mathrm{Ce}_{2} \mathrm{O}_{3}$ as starting materials. All raw materials were weighed at stoichiometric proportion and then mixed manually by a gate mortar. The mixed powder was calcined at $1200^{\circ} \mathrm{C}$ for $12 \mathrm{~h}$. After calcination, the mixture was milled again and pressed into pallet with a diameter of $6 \mathrm{~mm}$ and a thickness of $1 \mathrm{~mm}$ under the pressure of about $1 \mathrm{MPa}$. The ceramic was sintered at $1250^{\circ} \mathrm{C}$ for $8 \mathrm{~h}$.

The crystal structure of the powder was determined by X-ray diffraction (XRD) using a $\mathrm{Cu} \mathrm{K}_{\alpha}$ radiation $(\lambda=$ $1.54178 \AA$ ). The morphology, structure and size of the ceramic were characterized with scanning electron microscopy (SEM). The temperature dependence of the dielectric properties of the ceramic was performed using a HP 4284A LCR meter.

\section{Results and Discussion}

Figure 1 shows XRD pattern, which was identified as orthorhombic (JCPDS 49-0609) with space group A2 $2_{1}$ am. The lattice parameters were calculated using program Unit Cell: a $=5.53290 \AA, \mathrm{b}=5.52195 \AA$ and $\mathrm{c}=25.02979$ $\AA$. The strongest diffraction peak at $30^{\circ}$ is correlated to the $\left(\begin{array}{lll}1 & 1 & 5\end{array}\right)$ orientation, which is consistent with the $(11$ $2 \mathrm{~m}+1$ ) highest diffraction peak in bismuth layer-structured ferroelectrics [8]. The crystallite size was calculated from the (1 15 ) XRD peak using the Debye-Sherrer's equation [9], this was calculated to be $1221 \mu \mathrm{m}$.

Figure 2 shows room temperature Raman spectra of SBCT powder. The bands $\left(89\right.$ and $\left.131 \mathrm{~cm}^{-1}\right)$ assigned to the $\mathrm{Bi}-\mathrm{O}$ bonds [10], which reflect the vibration of $\mathrm{Bi}^{3+}$ ions in $\left(\mathrm{Bi}_{2} \mathrm{O}_{2}\right)^{2+}$ layer and Sr-Site $\mathrm{Bi}^{3+}$ ions. According to references [11] [12], the band around $130 \mathrm{~cm}^{-1}$, it may be attributed to the intercorporation of Ce/Bi.

J. S. Zhu et al. [13], reported that the Raman mode at $160 \mathrm{~cm}^{-1}$ corresponds to the Ta z-axis vibration, the 206 $\mathrm{cm}^{-1}$ band represent the $\mathrm{SrO}$ vibration with a rock salt structure, the band at about $602 \mathrm{~cm}^{-1}$ is associated with

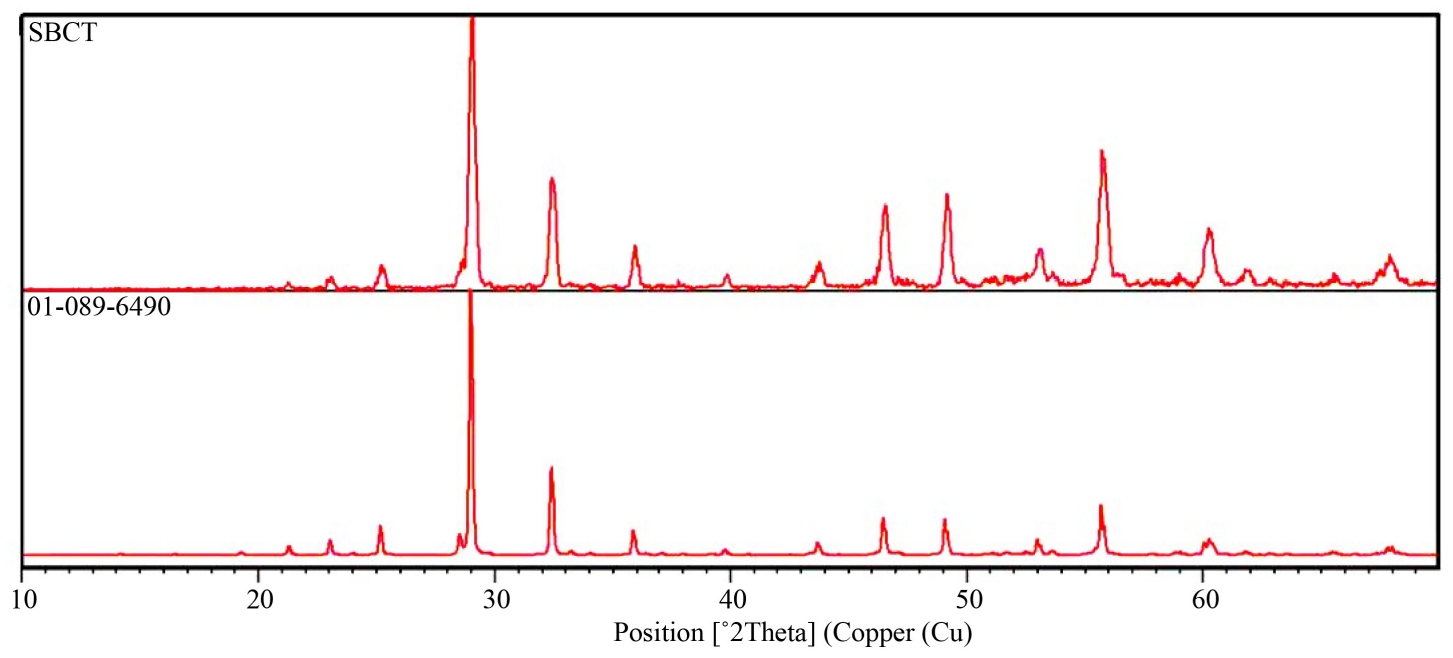

Figure 1. X-ray diffraction pattern of SBCT. 
the internal vibration of the $\mathrm{TaO}_{6}$ octahedron and the one at about $812 \mathrm{~cm}^{-1}$ is also related to the stretching mode of $\mathrm{TaO}_{6}$ octahedron.

Figure 3 shows SEM images of the SBCT ceramic. It can be seen that the ceramic has a plate-like morphology. This plate-like morphology of the grain is a characteristic feature of bismuth layer compounds [14]. The grain size is found to be slightly coarsened to $2 \mu \mathrm{m}-900 \mathrm{~nm}$, small amounts of pores still exist.

Figure 4 shows the frequency dependence of the dielectric constant and loss tangent measured at room temperature. The dielectric constant tends to be constant and the overall tangent loss was found to be below the $5 \times$ $10^{-2}$ through the frequency range studied.

Figure 5 shows the temperature dependence of the (b) dielectric constant $\left(\varepsilon^{\prime}\right)$ and (a) dielectric loss $(\tan \delta)$ of SBCT ceramic at $100 \mathrm{~Hz}$ and $1 \mathrm{kHz}$. The dielectric dispersion with frequency is significant at higher temperature. Well, it can due to the phenomena of space charge effects. This phenomenon was reported in detail by D. Dhak et al. [15]. The Curie temperature was around $330^{\circ} \mathrm{C}$ and dielectric peak was found to be $115 \mathrm{at} 1 \mathrm{kHz}$.

The dielectric loss $\left(\tan \delta\right.$ ) values as a function of temperature tend to be constant below $300^{\circ} \mathrm{C}$. But, above the latter temperature, $\tan \delta$ increases with the increase of temperature, which might be due to the oxygen vacancies.

Figure 6(a) shows the variation of reciprocal dielectric constant with temperature at $100 \mathrm{~Hz}$. It was found that the dielectric of SBCT deviates slightly the Curie-Weiss low.

$$
\varepsilon^{\prime}=\frac{C}{T-T_{C W}}
$$

where $C$ is the Curie constant and $T_{C W}$ is the Curie-Weiss temperature. The Curie-Wiess constant was found to be $0.8 \times 10^{5} \mathrm{~K}$ and the Curie-Wiess temperature is $320^{\circ} \mathrm{C}$. These results suggest using Curie-Weiss modified [16].

$$
\frac{1}{\varepsilon^{\prime}}-\frac{1}{\varepsilon_{m}^{\prime}}=\frac{C}{\left(T-T_{C}\right)^{\gamma}}
$$

where $C$ is the modified Curie-Weiss constant and $\varepsilon_{m}$ ' is the maximum dielectric constant. However, the relaxation factor $\gamma$ was found to be approximately 0.9, according to the fitting result shown in Figure 6(b). This is why the para-ferroelectric phase transition of the SBCT was regarded as non-relaxation.

Figure 7 shows the temperature dependence of ac conductivity of SBCT sample. The curve shows two regions: 1 ) at lower temperatures, the conductivity tends to be constant. It may be attributed to extrinsic conduction and a lattice defect; 2) in the high-temperature region, the conductivity increases with increasing temperature. Also, the activation energy calculated using the Arrhenius equation [17] was found to be $0.4 \mathrm{eV}$. According to Yun Wu et al. [18], the activation energy for $\mathrm{SrBi}_{2} \mathrm{Ta}_{2} \mathrm{O}_{9}$ is close to $1 \mathrm{eV}$. This difference, it may be due to the bond dissociation energy (enthalpy change) for a bond Ce-O (795 kJ/mole) is higher than Bi-O (343 kJ/mole) [19].

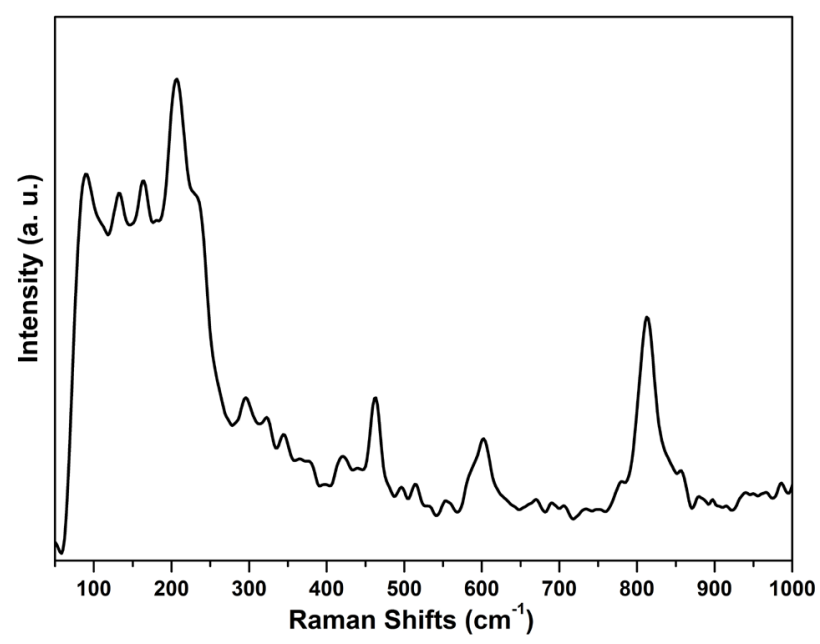

Figure 2. Raman spectrum of SBCT sample. 

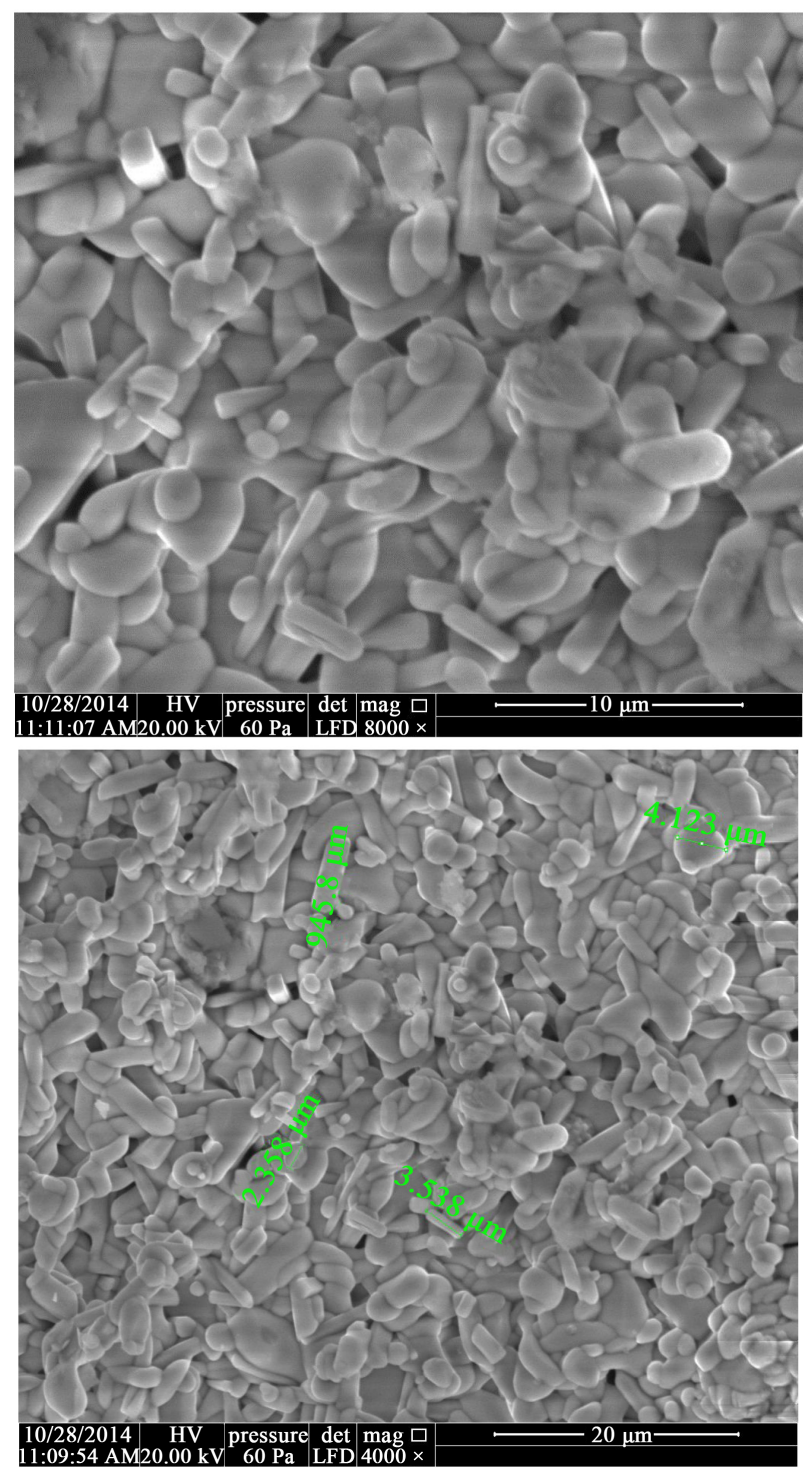

Figure 3. SEM images of sintered pellet of SBCT ceramic.

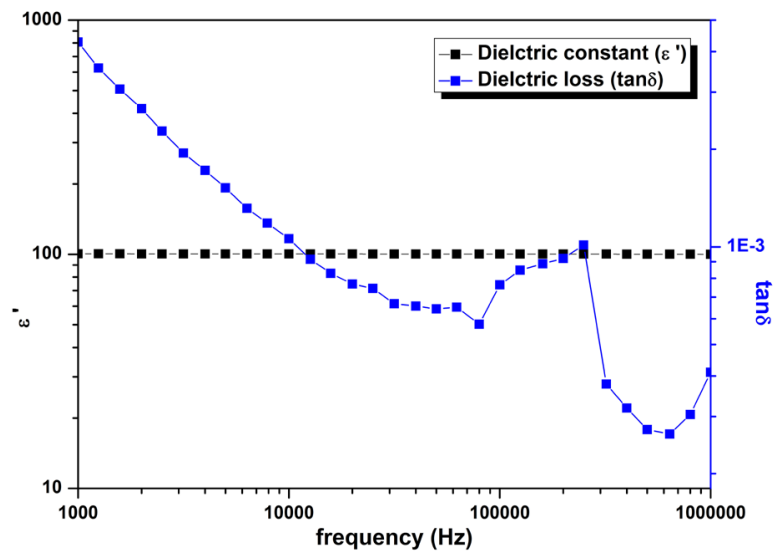

Figure 4. Frequency dependence of the dielectric of constant and loss tangent measured at room temperature of SBCT ceramic. 


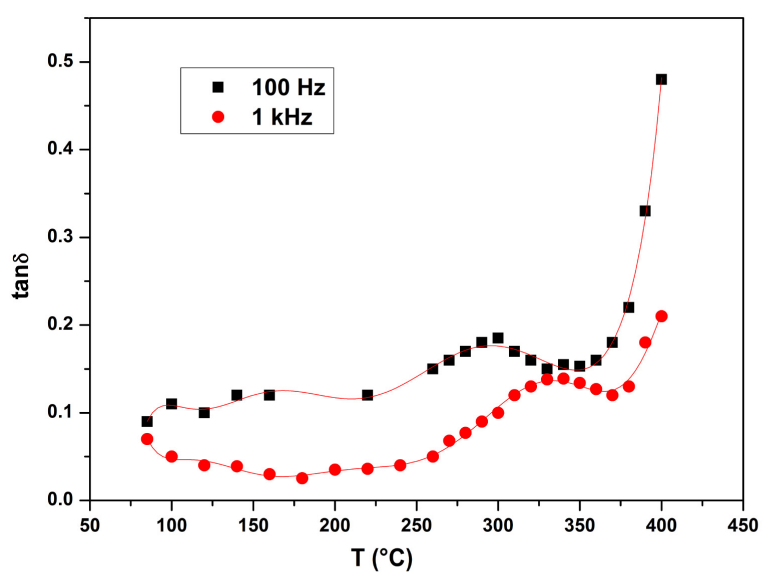

(a)

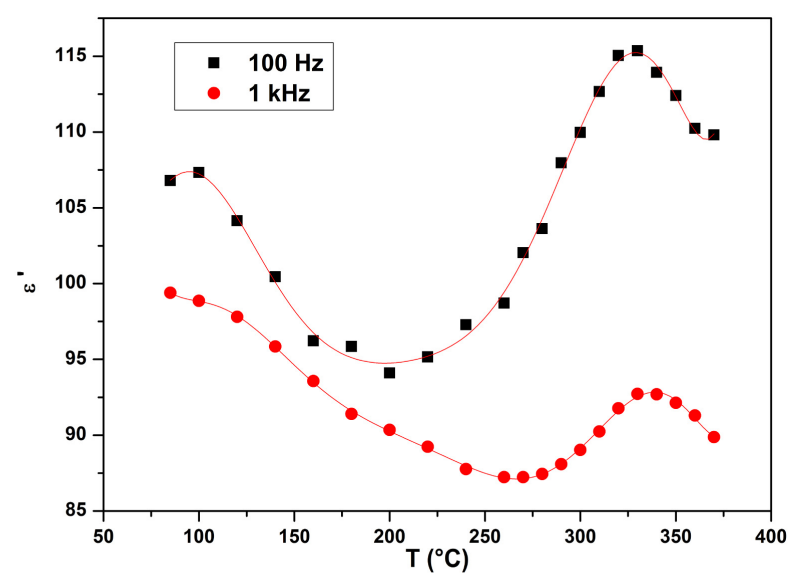

(b)

Figure 5. Variation of (b) dielectric constant $\left(\varepsilon^{\prime}\right)$ and (a) dielectric loss ( $\tan \delta$ ) respectively with temperature of SBCT ceramic.

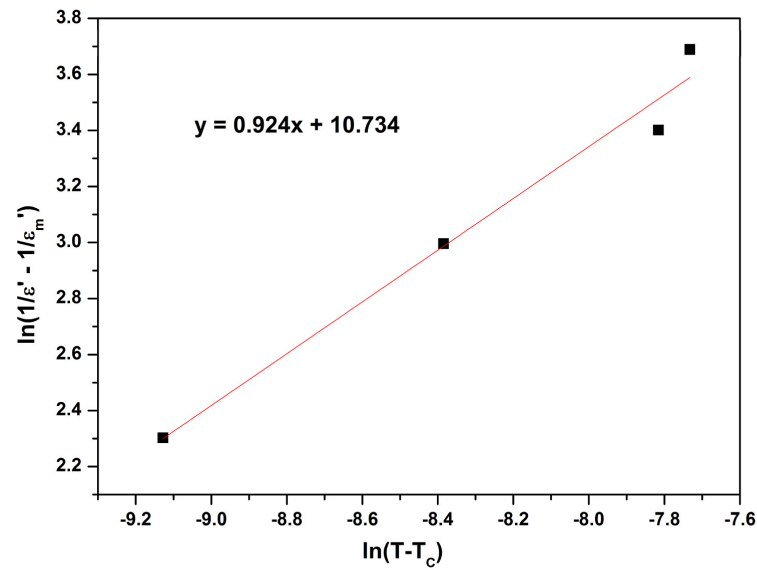

(a)

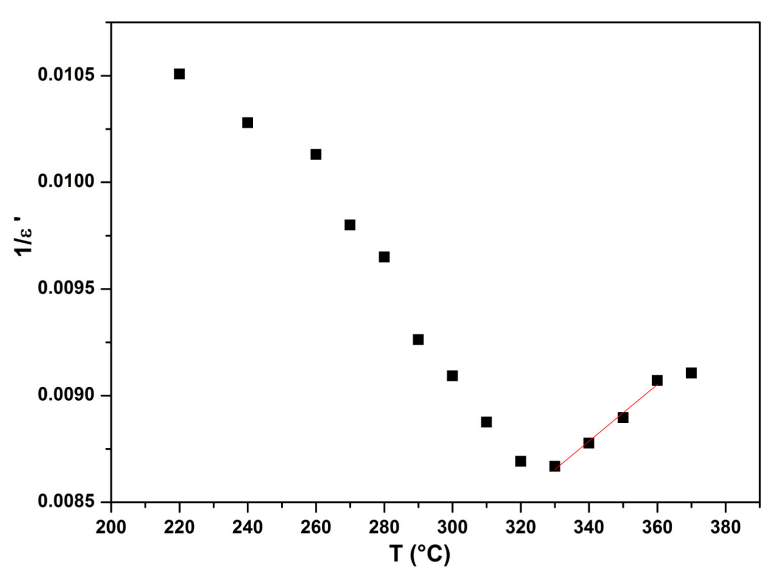

(b)

Figure 6. (a) Inverse dielectric constant ( $\left.\varepsilon^{\prime}\right)$ as function of temperature at $100 \mathrm{~Hz}$; (b) $\ln \left(1 / \varepsilon^{\prime}-1 / \varepsilon_{m}^{\prime}\right)$ vs. $\ln \left(1 / T-1 / T_{C}\right)$ at $100 \mathrm{~Hz}$ of SBCT ceramic.

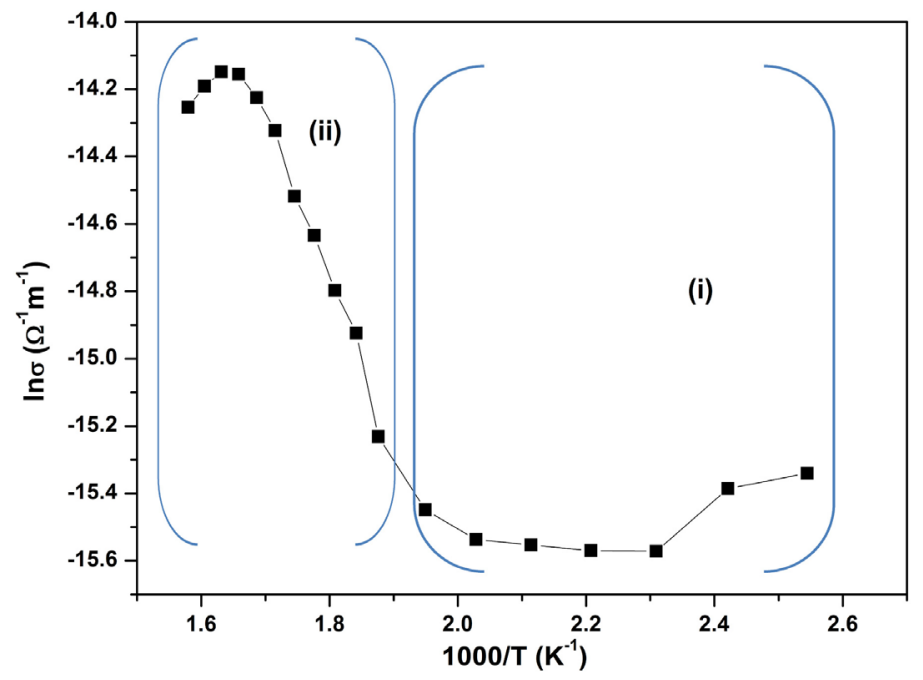

Figure 7. The variation of conductivity in SBCT ceramic as a function of temperature. 


\section{Conclusion}

$\mathrm{SrBi}_{1.8} \mathrm{Ce}_{0.2} \mathrm{Ta}_{2} \mathrm{O}_{9}$ was prepared by solid state reaction route. XRD analysis in $\mathrm{SrBi}_{1.8} \mathrm{Ce}_{0.2} \mathrm{Ta}_{2} \mathrm{O}_{9}$ showed the orthorhombic crystal structure. The Raman study confirms the XRD result. Plate-like structure and poor microstructure were observed from the SEM figures. The point of view dielectric measurements, a normal ferroelectric is observed and the activation energy calculated is assumed to the chemical bond.

\section{References}

[1] Isupov, V.A. (2006) Systematization of Aurivillius-Type Layered Oxides. Inorganic Materials, 42, 1094-1098. http://dx.doi.org/10.1134/S0020168506100086

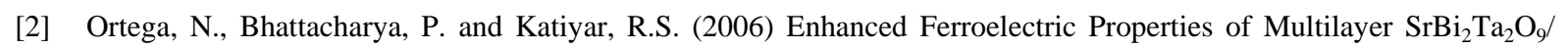
$\mathrm{SrBi}_{2} \mathrm{Nb}_{2} \mathrm{O}_{9}$ Thin Films for NVRAM Applications. Materials Science and Engineering, 130, 36-40. http://dx.doi.org/10.1016/j.mseb.2006.02.006

[3] Moert, M., Mikolajick, T., Schindler, G., Nagel, N., Igor, K., Hartner, W., Dehm, C., Kohlstedt, H. and Waser, R. (2005) Integration of Stacked Capacitor Module with Ultra-Thin Ferroelectric $\mathrm{SrBi}_{2} \mathrm{Ta}_{2} \mathrm{O}_{9}$ Film for High Density Ferroelectric Random Access Memory Applications at Low Voltage Operation. Thin Solid Films, 473, 328-334. http://dx.doi.org/10.1016/j.tsf.2004.08.087

[4] Kayani, Z.N. and Naseem , S.R. (2009) CODEN JNSMAC.

[5] Lu, C.H. and Chen, Y.Ch. (1999) Sintering and Decomposition of Ferroelectric Layered Perovskites: Strontium Bismuth Tantalate Ceramics. Journal of the European Ceramic Society, 19, 2909-2915. http://dx.doi.org/10.1016/S0955-2219(99)00076-X

[6] Senthil, V., Badapanda, T., Chandrabose, A. and Panigrahi, S. (2015) Dielectric and Ferroelectric Behavior of Cerium Modified $\mathrm{SrBi}_{2} \mathrm{Ta}_{2} \mathrm{O}_{9}$ Ceramic. Materials Letters, 159, 138-141. http://dx.doi.org/10.1016/j.matlet.2015.06.093

[7] Pavlovic, N., Koval, V., Dusza, J. and Srdic, V.V. (2001) Effect of Ce and La Substitution on Dielectric Properties of Bismuth Titanate Ceramics. Ceramics International, 37, 487-492. http://dx.doi.org/10.1016/j.ceramint.2010.09.005

[8] Yao, Z., Li, H., Ma, M., Chu, R., Xu, Z., Hao, J. and Li, G. (2015) Effect of Ce and La Substitution on Dielectric Properties of Bismuth Titanate Ceramics. Ceramics International, 37, 487-492.

[9] Suryanarayana, C. and Grant, N. (1969) X-Ray Diffraction: A Practical Approach.

[10] Oliveira, R.C., Cavalcante, L.S., Sczancoski, J.C., Aguiar, E.C., Espinosa, J.W.M., Varela, J.A., Pizani, P.S. and Longo, E. (2009) Synthesis and Photoluminescence Behavior of $\mathrm{Bi}_{4} \mathrm{Ti}_{3} \mathrm{O}_{12}$ Powders Obtained by the Complex Polymerization Method. Journal of Alloys and Compounds, 478, 661-670. http://dx.doi.org/10.1016/j.jallcom.2008.11.115

[11] Zhou, D., Gu, H.S., Hu, Y.M., Qian, Z.L., Hu, Z.L., Yang, K., Zou, Y.N., Wang, Z., Wang, Y., Guan, J.G. and Chen, W.P. (2010) Raman Scattering, Electronic, and Ferroelectric Properties of Nd Modified Bi4Ti3O12 Nanotube Arrays. Journal of Applied Physics, 107, 094105-094105-6.

[12] Li, J., Li, P. and Yu, J. (2015) Ferroelectrics. www.intechopen.com

[13] Zhu, J.S., Qin, H.X., Bao, Z.H., Wang, Y.N., Cai, W.Y., Chen, P.P., Lu, W., Chan, H.L.W. and Choy, C.L. (2001) X-Ray Diffraction and Raman Scattering Study of SrBi2Ta2O9 Ceramics and Thin Films with Bi3TiNbO9 Addition. Applied Physics Letters, 79, 3827-3829.

[14] Du, H. and Shi, X. (2011) Dielectric and Piezoelectric Properties of Barium-Modified Aurivillius-Type $\mathrm{Na}_{0.5} \mathrm{Bi}_{4.5}$ $\mathrm{Ti}_{4} \mathrm{O}_{15}$. Journal of Physics and Chemistry of Solids, 72, 1279-1283. http://dx.doi.org/10.1016/j.jpcs.2011.07.023

[15] Dhak, D., Dhak, P. and Pramanik, P. (2008) Influence of Substitution on Dielectric and Impedance Spectroscopy of $\mathrm{Sr}_{1}$ ${ }_{-x} \mathrm{Bi}_{2}+y \mathrm{Nb}_{2} \mathrm{O}_{9}$ Ferroelectric Ceramics Synthesized by Chemical Route. Applied Surface Science, 245, 3078-3092. http://dx.doi.org/10.1016/j.apsusc.2007.10.097

[16] Tian, H., Yao, B., Wang, L., Tan, P., Meng, X., Shi, G. and Zhou, Z. (2015) www.nature.com/scientificreports/

[17] Buchanan, R.C. (1998) Ceramic Materials for Electronic: Pressing, Proprieties and Applications. Marcel Dekker Inc., New York.

[18] Wu, Y., Forbess, M.J., Seraji, S., Limmer, S.J., Chou, T.P. and Cao, G. (2001) Impedance Study of $\operatorname{SrBi}_{2} \mathrm{Ta}_{2} \mathrm{O}_{9}$ and $\mathrm{SrBi}_{2}\left(\mathrm{Ta}_{0 \cdot 9} \mathrm{~V}_{0 \cdot 1}\right)_{2} \mathrm{O}_{9}$ Ferroelectrics. Materials Science and Engineering, 86, 70-78. http://dx.doi.org/10.1016/S0921-5107(01)00657-2

[19] Cottrell, T.L. (1958) The Strengths of Chemical Bonds. 2nd Edition, Butterworth, London. 